\title{
Power Quality Survey in a State of the Art Microgrid
}

\author{
H. Kirkeby ${ }^{1}$ and O. Johansson ${ }^{2}$ \\ ${ }^{1}$ PQA AS \\ Skippergata 22, 0154 Oslo (Norway) \\ Phone number: +47 47329 664, e-mail: henrik@pqa.no \\ ${ }^{2}$ Sivilingeniør Carl Christian Strømberg AS \\ Stabburveien 1 A, 1617 Fredrikstad (Norway) \\ Phone number: +47 95794 272, e-mail: ola@ solcellespesialisten.no
}

\begin{abstract}
The power quality in a state of the art microgrid has been examined using power quality analysers from Elspec Ltd and A-Eberle GmbH. The microgrid employs PV, CHP and three battery banks with a total of $120 \mathrm{~kW} / 204 \mathrm{kWh}$ dividing the microgrid into three subnetworks with different network topologies.

Different power quality measurements during different stages of construction shows that there are some power quality issues in the microgrid. These issues relate to transitioning to island mode, increase of harmonic noise during island mode, and undesirable equipment interactions. These are increasingly important issues to address as microgrids are becoming more widely adopted and increasingly complex.
\end{abstract}

\section{Key words}

Microgrid, Power Quality, Islanding detection, Control.

\section{Introduction}

Once an engineering novelty mostly used in demonstration projects, microgrids are becoming increasingly relevant and adopted. Navigant research estimated in 2018 that the microgrid market will develop to 30,9 billion USD market in 2027 , and currently about $1,5 \mathrm{GW}$ capacity of grid tied microgrids are installed globally [1].

US Department of Energy's definition of a microgrid is: "A microgrid is a group of interconnected loads and distributed energy resources within clearly defined electrical boundaries that acts as a single controllable entity with respect to the grid. A microgrid can connect and disconnect from the grid to enable it to operate in both grid-connected or island-mode". That a microgrid can island and control exchanged power with the grid opens a wide range of possible uses, from increasing grid resiliency, providing backup power, postponing network investments, increasing grid hosting capacity for distributed generation, etc.
Earlier most microgrid research were done on control, but as the technology matures more focus is moved towards challenges such as providing adequate power quality and stability [2]. This article aims to highlight some of the power quality issues faced in state of the art microgrids, that employs more complex schemes than earlier.

In Norway there have been few microgrid projects, but this is currently changing. The most significant current projects include:

- $\quad$ Skagerak Energilab, a football stadium with 700 kWp PV and a 1 MWh battery ${ }^{1}$.

- Sandbakken microgrid, a recycling plant for waste with $200 \mathrm{kWp} \mathrm{PV}, 3 \mathrm{~kW}$ wind turbines, and $100 \mathrm{~kW}$ energy storage [3].

- Campus Evenstad, a microgrid examined in this paper, described in chapter 2 .

Various power quality measurements have been performed during construction of Campus Evenstad microgrid, in order to examine possible power quality issues. This paper summarizes the most significant findings of these power quality surveys. The microgrid design is presented in chapter 2 and the measurements results in chapter 3 . Chapter 4 concludes the paper with the significance of the findings in chapter 3 .

\section{Microgrid design}

\section{A. Current Design}

The Campus Evenstad microgrid general design is pictured in figure 1 . The generation sources are $60 \mathrm{kWp}$ $\mathrm{PV}$, a $40 \mathrm{~kW}$ CHP machine, and the regulation is performed with three battery banks that power three different sections of the microgrid. Section BB2 and BB3 are set up as virtual IT-grids (230 V line to line, modelled

${ }^{1} \mathrm{https} / / /$ www.skageraknett.no/skagerakenergilab/category1560.html (in Norwegian). 


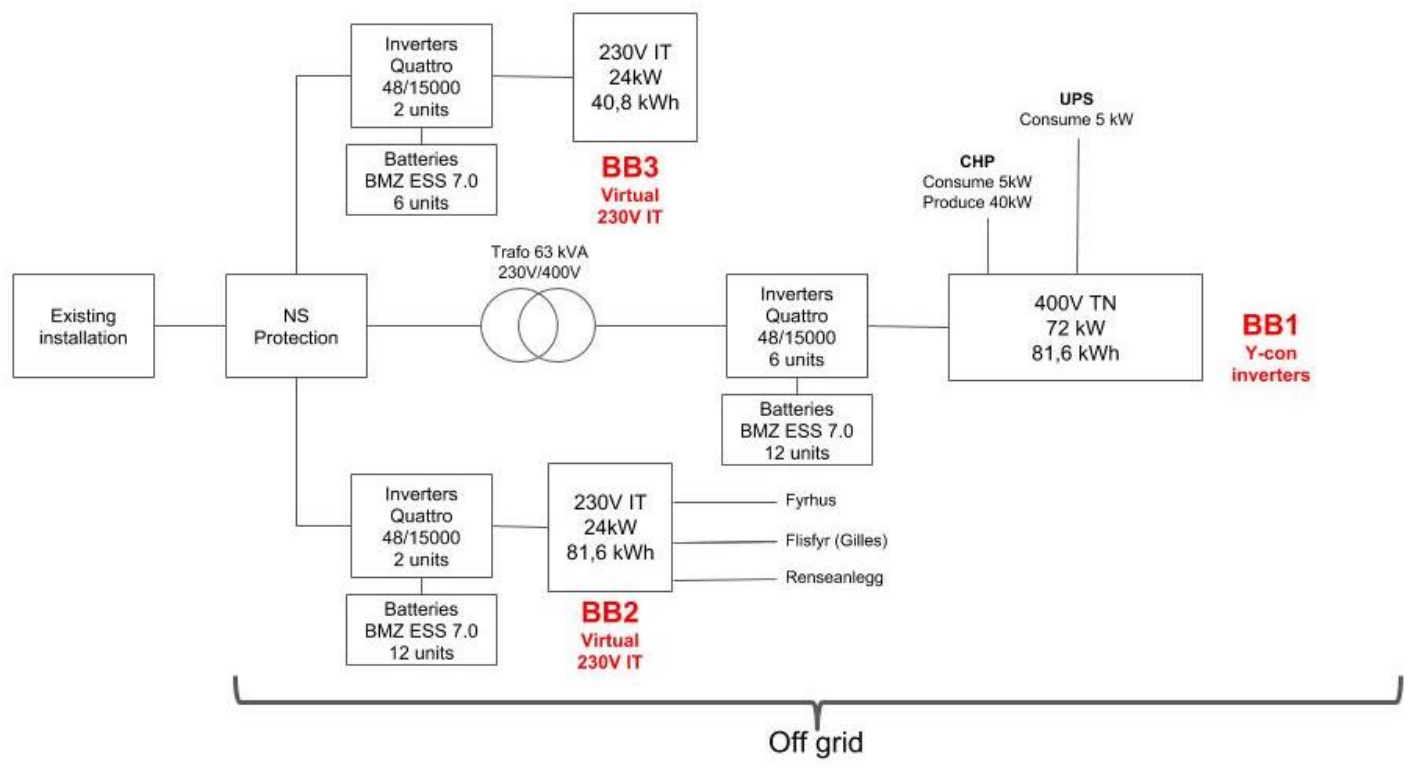

Figure 1: Current layout of the Campus Evenstad microgrid.

using to $230 \mathrm{~V}$ converters connected in $\mathrm{V}$ ) and section BB1 is fed through a 230/400 V transformer and three Y connected converters. Under BB1 there is currently connected an UPS and the CHP machine, while BB2 and BB3 serves all other load in the installation.

\section{B. Future Design}

By 2020 the microgrid is to be further developed and will include a V2G charger as well as other new functionality.

\section{Power Quality Measurements}

The power quality in the microgrid has been examined with three different instruments (Elspec G4420, Elspec G4500, and A-Eberle PQ-Box 300), on three different occasions. The reason for this was partially to benchmark the different power quality analysers, and two keep track of power quality influence during different stages of construction of the microgrid.

\section{A. Measurement results from August 23. to 31.}

During this period the G4500 was used, and the PQ-Box 300 was used shortly during the start of the measurements. Both instruments were installed at BB1 (see figure 1).

The most interesting finding from this period was that during transitioning from grid connected to island mode, the islanding detection did not work as anticipated. This is shown in figure 2 as measured with the $\mathrm{G} 4500^{2}$.

\footnotetext{
2 There was a difference in minimum voltage during the voltage dip when compared with the PQ-Box measurements. This is due to a temporary increase of tolerance limits in the G4500, which leaves all other frequency components than the fundamental measured incorrectly. The correct minimum voltage dip measured during this islanding period was $85 \mathrm{~V}$.
}

As figure 2 depicts, there is an approximately 40 s period with a voltage swell on one phase (about $265 \mathrm{~V}$ ) before the battery converter BB1 activates islanding mode, and voltage is reduced to about $230 \mathrm{~V}$. There are some slow oscillations during a transitional period before the voltage stabilises, possibly caused by regulation in the battery converter. The microgrid reconnects to the grid at the right in the figure, and voltage increase to grid voltage $(238 \mathrm{~V})$.

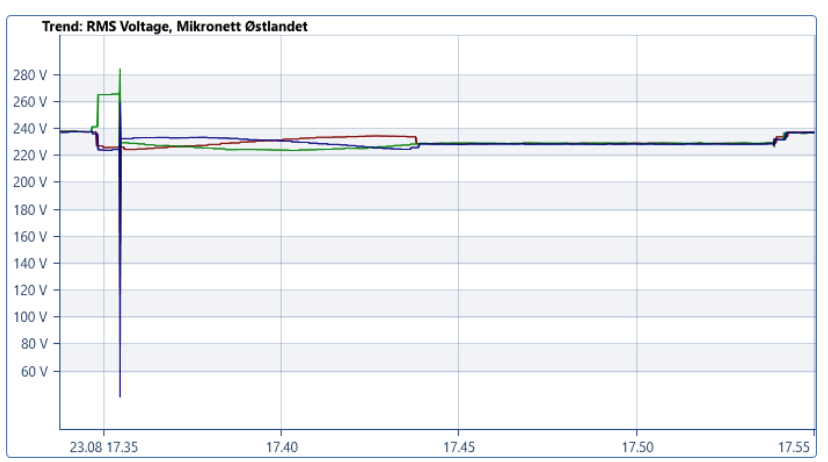

Figure 2: Voltages measured with a G4500 during a 20-minute islanding period.

The transitional event is also measured with the PQ-Box, which gives a lower time resolution, but shows similar measurements as with the G4500 in figure 2. 


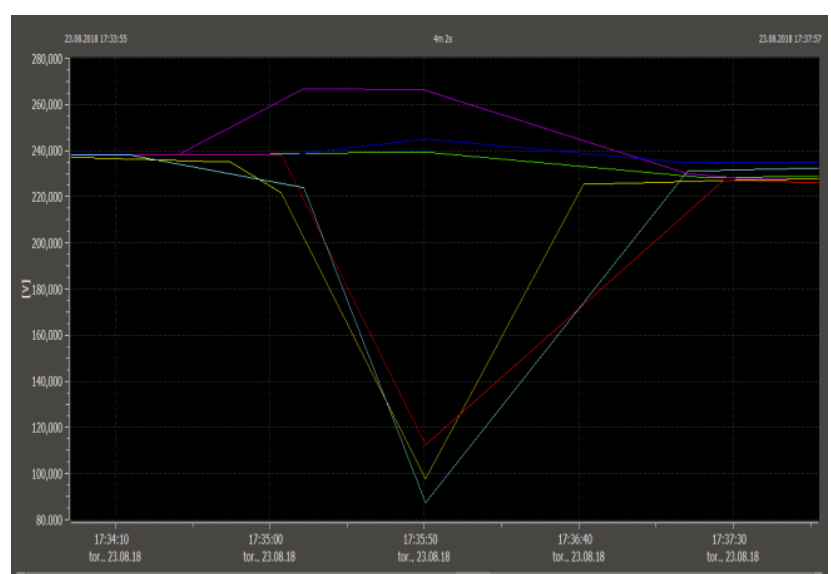

Figure 3: Min $(85 \mathrm{~V})$ and $\max (267 \mathrm{~V})$ voltages per minute, measured with a PQ-Box 300 during the transition to islanding in the same islanding as in figure 2 .

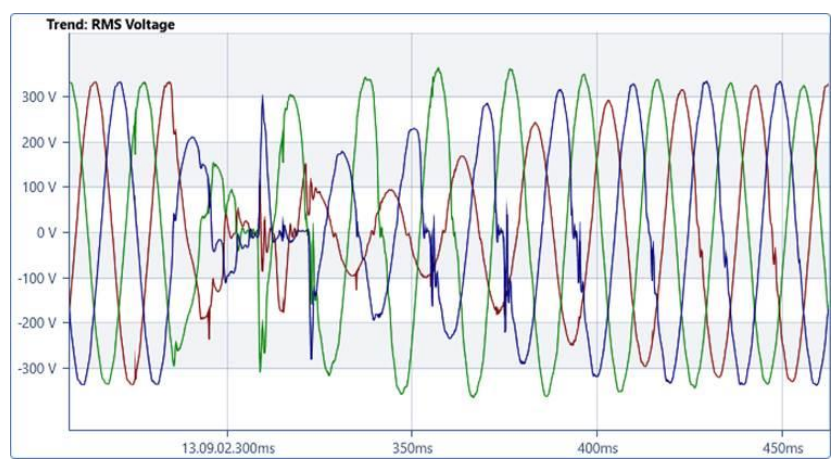

Figure 4: Voltage waveform during another islanding transition.

In addition to challenges with islanding detection, there were also relatively large voltage dips when the bypass mode in the converter was deactivated. One of the cases this happened is shown in figure 4 . This voltage dip is long and deep enough that it appears in the "No damage region" in the ITIC curve, showed in figure 5. In other words, it would be expected that various IT-equipment might trip or restart during this islanding transition.

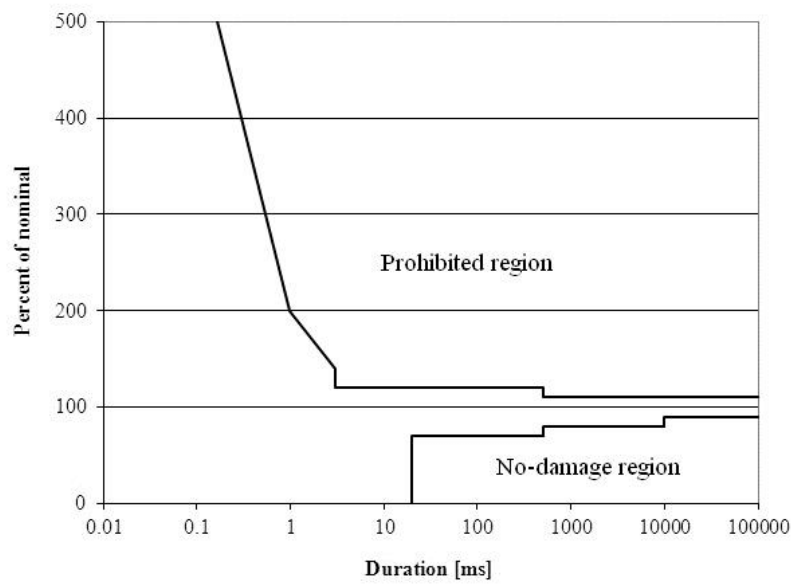

Figure 5: ITIC-curve

The PQ-Box 300 was also used to measure supraharmonic ${ }^{3}$ emission in the microgrid. This is shown in figure 6 . The

${ }^{3}$ Harmonics with frequency between 2 and $150 \mathrm{kHz}$, often caused by power electronic switching or power line communication (PLC). dominant frequency here is the battery system converter, with a switching frequency of about $20 \mathrm{kHz}$. Noise levels are low in the beginning of the figure, in grid connected mode, zero during a period where the instrument was disconnected, and high when the microgrid is islanded, as expected in a grid with reduced short circuit power. This highlights the issue that reduced short circuit capacity in microgrids might increase challenges observed elsewhere with supraharmonic interference [4]. Other measurements also showed that the $15^{\text {th }}$ harmonic increases above regulatory limits during island mode, although this is not uncommon to happen for household installation either.

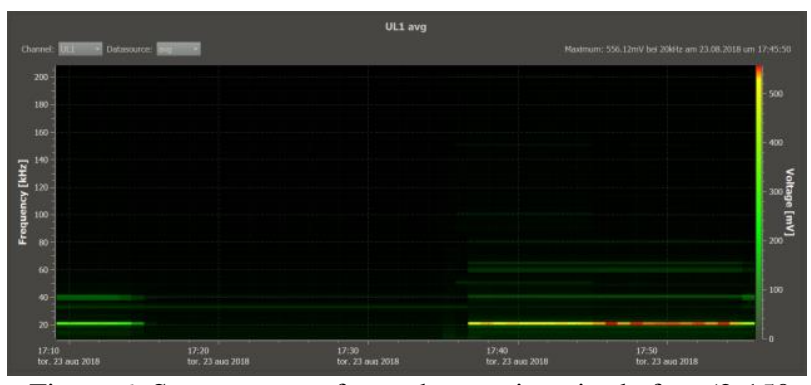

Figure 6: Spectrogram of supraharmonic noise before (2-150 $\mathrm{kHz}$ ), during and after an islanding (instrument disconnected in the middle). Peak value is $556 \mathrm{mV}$.

The G4500 is also able to detect the switching noise, but this is at the far end of what this instrument can measure (theoretically up to $25 \mathrm{kHz}$ ).

\section{B. Measurement results from October $8^{\text {th }}$ to $10^{\text {th }}$}

During the second measurement campaign, there were more extensive testing, and therefore several islanding transitions. Measurements were done on BB1, and only with the PQ-Box 300. An overview over the complete testing period is shown in figure 7 , which shows that islanding routinely causes voltage swells and voltage dips (some of the events are outages when the battery bank was disconnected).

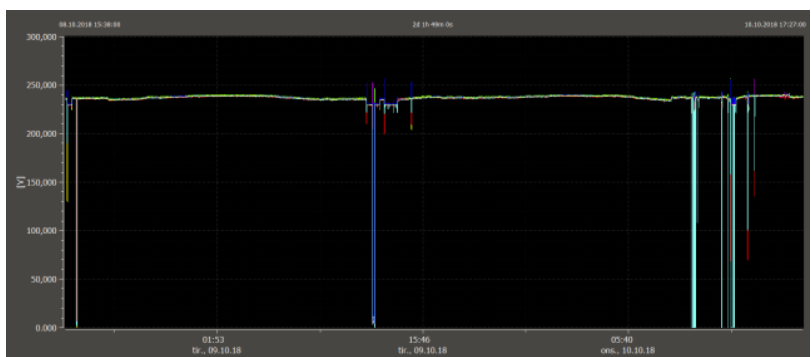

Figure 7: RMS phase voltage during the measurement period.

The most severe islanding transition during this period is shown in figure 8 . Not only does this transition cause a large voltage drop and voltage variations; there are significant current oscillations during zero crossing on L2 after the voltage has returned to nominal value. Peak oscillations are about 10 times stationary value. The probable cause for these oscillations is interaction between the converter and the UPS, which is connected to the BB1 battery bank. 


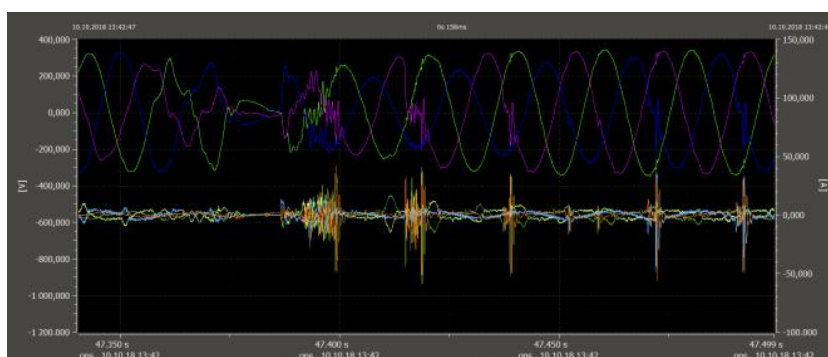

Figure 8: Voltage and current waveform during the most severe islanding transition. Peak current is close to $50 \mathrm{~A}$.

\section{Measurement results from October $16^{\text {th }}$ to present date}

For future troubleshooting and research, there has been placed continuous power quality measurements in the microgrid (a G4420 Blackbox). During construction these will be used to troubleshoot ongoing issues, and then later as a source for power quality data that for further research and development.

\section{Conclusion}

A study of power quality in a state of the art microgrid shows several challenges that might be relevant for other installations:

1. Transitioning to island mode is demanding. This is partly due to difficulty in islanding detection in more advanced installation where different systems can interfere with each other. Furthermore, the voltage dips during transitional periods might affect connected equipment, and possibly also damage it, even though it is supposed to be able to withstand these voltage variations.

2. Harmonic noise increases during islanded mode, when short circuit power is reduced. In this case noise levels were low, partially due to light loading of the microgrid. In other cases, increased noise levels during islanding might lead to EMI, which can be difficult to both detect and solve.
3. Integrating several sources with different types of control, including thermal and heating systems, situated in different network topologies can be very challenging. Making systems work together might require configuration changes in some of the equipment, which might cause suppliers to withdraw equipment guarantees. Complex systems also increase the risk of unintended controller interactions.

By documenting these challenges, the authors hope to both inform other microgrid developers, and suppliers to create new systems that addresses some of these issues.

\section{Acknowledgement}

This paper is written in the research project EMC i smarte nett (EMC in smart grids), supported by the Research Council of Norway in the ENERGIX programme. The project is also supported by the Norwegian Water and

Energy Regulator (NVE) and five Norwegian utilities (Lyse Elnett, NTE Nett, Skagerak Nett, Hafslund Nett and Eidsiva Nett), who are project members. Energi Norge, Solenerigklyngen, Smartgridsenteret and Elbilforeningen are also participating members in the project.

The Campus Evenstad microgrid has generously been made available for the power quality measurements by the owner, Statsbygg.

\section{References}

[1] Navigant Research, "Market Data: Microgrids, Annual Capacity and Implementation Spending by Geographic Region, Market Segment, and Business Mode”, 2018.

[2] Y. Yoldaş, A. Önen, S.M.Muyeen, A.V.Vasilakos. I. Alan, "Enhancing smart grid with microgrids: Challenges and opportunities", in Renewable and Sustainable Energy Reviews, 2017, Vol. 72, p. 205-214

[3] Schneider Electric, "D7.1: Pilot Sites Specification Report", version 2, EMPOWER H2020-project, 2016.

[4] CLC/SC205A, "Study Report on Electromagnetic interference between Electrical Equipment/Systems in the Frequency Range below $150 \mathrm{kHz}$ ", CENELEC, Edition 3, 2015. 